\title{
Al 7075-T651 Alaşımının Tornalanmasında Elmas Benzeri Karbon (DLC) Kaplama Performansının İncelenmesi
}

\author{
Nihat YILMAZ* \\ Isparta Uygulamalı Bilimler Üniversitesi, Teknoloji Fakültesi, Makine Müh. Bölümü, Isparta \\ (ORCID: 0000-0002-8689-1048)
}

\begin{abstract}
Öz
Havacılık, biyomedikal ve otomotiv endüstrisinde alüminyum alaşımlarının kullanımının yaygınlaşmasıyla birlikte, bu malzemelerin işleme davranışları ve işleme problemleri son yıllarda ilgi konusu olmuştur. Kuru işlemede, alüminyum gibi yüksek plastisiteye sahip (sünek) metaller, takım-talaş ara yüzeyinde geniş temas alanı, yüksek sürtünme katsayısı ve sıvanma (adezyon) özellikleri ve buna bağlı olarak güçlü bir talaş yığılması (BUE) eğilimine sahiptir. Bu çalışmada alüminyum alaşımlarının bu problemine bir çözüm olarak son yıllarda yoğun çalışmaların yapıldığı DLC (diamond-like carbon) kaplamanın performansı Al 7075-T651 alaşımı için incelenmiştir. K10 standardına sahip sinterlenmiş karbür takım, üç farklı kaplama şartlarında (kaplamasız, ticari kaplamalı ve DLC kaplamalı) kullanılmıştır. Çalışmada DLC kaplama işlemi özgün olarak yapılmıştır. Bu takımların Al 7075-T651 alüminyum alaşımının işlenmesi sırasındaki performansı tornalama testleriyle gerçekleştirilmiştir. Tornalama işleminde talaş derinliği 1,5 mm sabit alınırken, 3 farklı kesme hızı $(300,400$ ve $500 \mathrm{~m} / \mathrm{dk})$ ve 3 farklı ilerleme hızı $(0,2-0,3$ ve 0,4 mm/dev) seçilmiştir. Sonuç olarak, DLC kaplamanın sıvanma sorununa çözüm olabileceği, ancak kaplama parametrelerinin, kesici takım ve alaşımın sınıfına bağlı olarak optimize edilmesi gerektiği değerlendirilmiştir.
\end{abstract}

Anahtar kelimeler: Alüminyum Alaşımı, Al 7075-T651, DLC kaplama, Tornalama.

\section{Investigation of Diamond-Like Carbon (DLC) Coating Performance in Turning of Al 7075-T651 Alloy}

\begin{abstract}
With the widespread use of aluminum alloys in the aerospace, biomedical and automotive industries, the machining behavior and machining problems of these materials have been of interest in recent years. In dry machining, metals with high plasticity (ductile) such as aluminum have a wide contact area at the tool-chip interface, high friction coefficient and smearing (adhesion) properties and a strong chip build-up (BUE) tendency. In this study, as a solution to this problem of aluminum alloys, the performance of DLC (diamond-like carbon) coating, which has been extensively studied in recent years, has been investigated for Al 7075-T651 alloy. Sintered carbide tool with K10 standard was used in three different coating conditions (uncoated, commercial coated and DLC coated). In the study, the DLC coating process was performed originally. The performance of these tools during the machining of Al 7075-T651 aluminum alloy has been performed by turning tests. While the depth of cut was fixed to $1.5 \mathrm{~mm}$ in the turning process, 3 different cutting speeds $(300,400$, and $500 \mathrm{~m} / \mathrm{min})$ and 3 different feed rates $(0.2-0.3$ and $0.4 \mathrm{~mm} / \mathrm{d})$ were selected. As a result, it was evaluated that DLC coating could be a solution to the smearing problem, but coating parameters should be optimized depending on the grade of the cutting tool and the alloy.
\end{abstract}

Keywords: Aluminum Alloy, Al 7075-T651, DLC coating, Turning.

\section{Giriş}

Otomotiv endüstrisi hem yakıt sarfiyatını hem de karbon emisyonlarını azaltmak için sürekli çaba sarf etmektedir. Günümüzde özellikle hibrit ve elektrikli araçların geliştirilmesi çalışmalarında, verimliliği artırmak ve daha hafif araçlar üretebilmek, kütlenin azaltılması ile mümkün olmaktadır. Bu amaçla başta otomotiv endüstrisi olmak üzere uzay-uçak endüstrisindeki hava araçlarında, savunma sanayii uygulamalarında hafif metallere olan ilgi artmıştır. Alüminyum alaşımları yapısal malzeme

*Sorumlu yazar: nihatyilmaz@isparta.edu.tr

Geliş Tarihi:25.05.2021, Kabul Tarihi: 14.08.2021 
uygulamalarında çelikten sonra magnezyum ve titanyumun yanı sıra en çok kullanılan demir dışı metalik malzemelerdir [1]. Spesifik mukavemetinin (mukavemet-yoğunluk oranı), korozyon direncinin, 1sı1elektriksel iletkenliğinin yüksek olmasının yanı sıra, toksik olmaması, yüksek sürtünme katsayısı, manyetik nötralite ve şekillendirme kabiliyeti gibi benzersiz özellikleri nedeniyle günümüzde birçok uygulamada demir esaslı malzemelerin yerine tercih edilmektedir. Alüminyum alaşımları, hafif yapılara yönelik artan talepler nedeniyle, genellikle hava ve kara ulaşım araçlarının ekipmanlarında yapısal konstrüksiyon elemanı olarak kullanılmaktadır. İmalat endüstrisinde alüminyum ve alaşımlarına talebin artmasıyla birlikte, işlenmesine yönelik artan bir ihtiyaç bulunmaktadır. [2-3]

$7 \mathrm{xxx}$ serisi dövme alüminyum alaşımları da özellikle havacılık ve uzay endüstrisinde, hava araçlarının gövde, iniş takımları ve hidrolik sistem bileşenleri gibi yapısal parçalarda tercih edilmektedir. Kullanımın artmasına paralel olarak alüminyum ve alaşımlarının işlenebilirlik şartlarının optimize edilmesi önem kazanmaktadır. Günümüzde, kuru şartlarda ve yüksek hızlı işleme için uygun yüksek performanslı takım malzemeleri dahil olmak üzere çevre dostu ve uygun maliyetli kesme teknolojilerinin geliştirilmesi için yoğun çalışmalar yapılmaktadır [4]. Bununla birlikte, kuru işlemede, alüminyum gibi yüksek plastisiteye sahip (sünek) metaller, malzeme-takım ara yüzeyinde geniş temas alanı, yüksek sürtünme katsayısı ve sıvanma (adezyon) özellikleri ve buna bağlı olarak güçlü bir talaş yığılması (BUE) eğilimine sahiptir [3]. BUE'nin yüksek kesme kuvveti, zayıf parça yüzey kalitesi ve kısa takım ömrünün ana nedeni olduğu bilinmektedir. Özellikle yüksek sıcaklıklarda süneklik artacaktır. $\mathrm{Bu}$ nedenle, alüminyum alaşımlarının talaşlı imalatı için kullanılacak kesici takımlarda, düşük afinite (kimyasal ilgi), düşük sürtünme katsayısı ve yüksek sertlik gibi özellikler önem kazanmaktadır. Alüminyum alaşımları gibi sünek malzemelerde karşılaşılan işleme problemleri; iş malzemesinin mukavemet ve sertliği artırılıp takım-talaş temas alanı azaltmakla, ya da takım-talaş ara yüzeyinde sürtünme katsayısını azaltacak şartlar örneğin uygun yüzey kaplamalar oluşturularak çözülebilir [3]. Son yıllarda, takıma sıvanma eğilimi yüksek metal alaşımlarının işlenmesinde, takım performansını iyileştirmek için kimyasal veya fiziksel buhar biriktirme ile üretilen birçok yüzey kaplaması uygulamaları geliştirilmiştir. Bunlar arasında, elmas ve elmas benzeri karbon (DLC) gibi karbon bazlı kaplamalar, BUE oluşumunu önemli ölçüde azaltma ve dolayısıyla kesme performansını iyileştirme yeteneği göstermiştir. Öte yandan, TiN, TiAlN ve CrN gibi geçiş metal nitrür kaplamaların, BUE oluşumu nedeniyle zayıf performans gösterdiği de literatürde belirtilmektedir. [4].

Campell vd. (2006) Al-7075-T651 dövme alaşımlarının yüksek hızda işlenmesi sonrası iş parçası ve talaşların mikro yapısını inceledikleri çalışmalarında, kaplamasız $0^{\circ}$ ve $15^{\circ}$ talaş açısına sahip sinterlenmiş karbür kesici takım kullanmışlardır. Talaş kaldırma işlemi $100 \mathrm{~mm}$ çapında boru numuneler üzerinde ortogonal kesme şeklinde yapılmıştır. Kesme parametreleri ise; kesme hızı $360 \mathrm{~m} / \mathrm{dk}$ ile 720 $\mathrm{m} / \mathrm{dk}$ arasında (üç kademe), ilerleme oran $10,076 \mathrm{~mm} / \mathrm{dev}$ değerinde sabit alınmıştır. Ayrıca işlem simülasyon programıyla da işleme prosesinin sıcaklık analiz yapılmıştır. Çalışmada işleme sonucu hem iş parçasının işlenmiş yüzeyinde hem de talaş yüzeyinde sertlikte azalma olduğu, ancak deformasyon tabakasının kalınlığının arttığı ve tanelerin parça ekseni boyunca uzadığı ifade edilmiş ve bunun da dinamik yeniden kristalleşmeye bağlı olarak çökeltilerin kabalaşması nedeniyle olabileceği literatür ıșığında yorumlanmıştır. Simülasyon sonuçlarıyla birleștirildiğinde ise artan kesme hızıyla birlikte artan deformasyon tabakası kalınlığı ve sıcaklığın hızlı difüzyonla çökeltileri kabalaştırdığı ifade edilmiştir. Böylece kesme hızının talaş ve iş parçası mikro yapıları üzerindeki etkisi karakterize edilmiştir [5]. Santos (2007) ve arkadaşları yaptıkları çalışmada, K-20 tipi üçgen geometriye sahip sinterlenmiş karbür kesici takım üzerine PECVD tekniğini kullanarak elmas benzeri karbon (DLC) ince film tabakası kaplamışlardır. Kaplama kalınlığı 2.5 mikron olarak belirlenen kesici takımlarla 30 Rochwell B sertliğindeki $150 \mathrm{~mm}$ çapında ve $200 \mathrm{~mm}$ uzunluğunda, iki farklı döküm Al-Si alaşımlarından hazırlanan numuneler tornalama işlemine tabi tutulmuştur. Kesme parametreleri; kesme hızı $450 \mathrm{~m} / \mathrm{dk}$, ilerleme oranı $0,15 \mathrm{~mm} /$ devir, kesme derinliği ise $0,5 \mathrm{~mm}$ olarak seçilmiş ve deneyler her test koşulu için 5 tekrar şeklinde yapılmıştır. Çalışmada kaplama karakterizasyonunun yanı sıra kesme işlemi sırasında oluşan kesme kuvvetleri de ölçülmüş̧ür. Çalışma sonucunda, ilerleme kuvvetinin, silikon içeriği fazla alüminyum alaşımında, düşük olana göre daha yüksek çıktığı görülmüsstür. Ayrıca DLC film kaplamanın, ilerleme kuvvetlerini her iki alaşım için \%10-15 mertebesinde esas kesme kuvvetini ise yine her ikisi için \%4-6 mertebesinde azaltma eğiliminde olmakla birlikte, farkın çok az olduğu da vurgulanmıştır [6]. Brzezinka vd. (2019) yaptıkları çalışmada, Al-Si alaşımlarını frezeleme işleminde tungsten karbür kesici ucu, karşılaştırma için genel kaplama olarak tek katmanlı TiB2 ile kaplamışlardır. Daha sonra bununla kıyaslama için farklı kaplama şartlarında tek katmanlı DLC kaplama ve çok 
katmanlı (2-6-12 ve 24 katmanlı) DLC-WS2 kapmaların performansını incelemişlerdir. Talaş kaldırma işlemi sonrası takımda oluşan serbest yüzey aşınmaları ve aşınma testleriyle sürtünme özellikleri değerlendirilerek, kaplama performansları karşılaştırılmıştır. Çalışmada, DLC kaplamaların takım-talaş ara yüzeyinde daha etkin bir yağlayıcı tabaka oluşturarak yapışma eğilimini azalttığı, özellikle çok katmanlı kaplamanın daha iyi sonuç verdiği belirtilmiş̧ir. Tek katmanlı DLC kaplamanın TỉB2 kaplamaya göre takım aşınma oranını \%85 azalttığı, çok katmanlı DLC kaplamaların ise tek katmanlıya göre daha iyi sonuç verdiği rapor edilmiştir [7]. Sahoo ve Datta (2020) kaplamasız ve MT-CVD TiCNA12O3 kaplamalı karbür kesici uçlar kullanılarak AA7075 T6 alaşımının kuru işleme performansını inceledikleri çalışmalarında $96,8 \mathrm{~mm}$ çapında ve $400 \mathrm{~mm}$ uzunluğunda silindirik numuneleri, 4 farklı kesme hiz1 ile (120-150-200-300 m/dk) sirasiyla sabit 0,1 mm/dev ilerleme oranı, 0,35 mm kesme derinliği parametrelerinde tornalamışlardır. İşleme performansı için teğetsel kesme kuvveti, takım ucu sıcaklığı ve serbest yüzey aşınması derinliği ölçülmüştür. Kaplamalı takımın performansı, kaplamasız kesici uç ile karşılaştırılmıştır. Kaplanmış takımın, kaplanmamış muadiline göre daha düşük takım ucu sıcaklığına ve daha az serbest yüzey aşınmasına neden olduğu görülmüsstür. Her iki takımda adezyon ve yığma tabaka oluşumunun yanı sıra; kaplamasız takımda abrasif ve difüzyon aşınması da görülmüştür [1].

Literatür incelendiğinde, genellikle alüminyum alaşımlarının işlenmesinde, talaş-takım ara yüzeyinde sıvanma ve yığıntı kenar oluşumunun en çok karşılaşılan işleme problemi olduğu görülmektedir. Bunun üstesinden gelmek içinde yapılan çalışmalar aşağıdaki gibi genelleştirilebilir;

1) Isıl işlemle (genellikle yaşlandırma) malzemenin sertliği artırılarak talaşın kolay kırılması ve temas uzunluğunun azaltılmas1 [8-10]

2) Takım-talaş ara yüzeyinin sürtünme şartlarını değiştirmek için kesme parametrelerinin veya takım geometrisinin optimizasyonu [11-14]

3) Genellikle kuru kesme tercih edilmekle birlikte, takım-talaş ara yüzeyinde sürtünme ve sıcaklığı azaltmak için ekolojik yağlama/soğutma yöntemlerinin uygulanması [15-18]

4) Takım-talaş ara yüzeyindeki sürtünmeyi azaltmak için kesici takımlara çeşitli kaplamalar uygulanmas1 [19-22, 7]

Gerçekleştirilen bu çalışmada Al 7075-T651 alüminyum alaşımının kuru tornalanması sırasında, kaplamasız, ticari kaplamalı ve DLC kaplamalı olmak üzere, üç farklı kaplama şartlarına sahip karbür takımın işleme performansı karşılaştırılmıştır.

\section{Materyal ve Metot}

Çalışmada 60 mm çapında 500 mm uzunluğunda hazırlanan A17075-T651 dövme alüminyum alaşımları ALEX ANL-75 markalı CNC torna tezgâhında işlenmiştir. T651 alüminyum alaşımına suni yaşlandırma ve gerilim giderme 1 sıl işlemleri uygulanmıştır. Bu malzeme genel olarak; uçak ve savunma endüstrisinde yüksek mukavemet gerektiren yerlerde, kauçuk ve plastik kalıplarda, kayak direklerinde, makina parçalarında, nükleer uygulamalarda ve otomotiv sanayisinde yaygın olarak kullanılmaktadır. Malzemenin kimyasal bileşimi Tablo 1'de, mekanik özellikleri Tablo 2'de verilmiştir.

Tablo 1. Al-7075 alaşımının kimyasal bileşimi (\% ağılık)

\begin{tabular}{|c|c|c|c|c|c|c|c|c|c|}
$\mathbf{F e}$ & $\mathbf{S i}$ & $\mathbf{C u}$ & $\mathbf{M n}$ & $\mathbf{M g}$ & $\mathbf{Z n}$ & $\mathbf{C r}$ & $\mathbf{T i}$ & $\mathbf{D i g ̆ e r}$ & $\mathbf{A l}$ \\
\hline 0,5 & 0,4 & $1,2-2,0$ & 0,3 & $2,1-2,9$ & $5,1-6,1$ & $0,18-0,28$ & 0,20 & 0,15 & Kalan \\
\hline
\end{tabular}

Tablo 2. Al 7075-T651 alaşımının bazı mekanik özellikleri

\begin{tabular}{|c|c|c|c|c|}
\hline Temper & $\begin{array}{c}\text { Akma Mukavemeti (MPa) } \\
\text { min-max }\end{array}$ & $\begin{array}{c}\text { Çekme Mukavemeti (MPa) } \\
\text { min-max }\end{array}$ & $\begin{array}{c}\text { Uzama (\%) } \\
\text { min-max }\end{array}$ & $\begin{array}{c}\text { Sertlik (HRB) } \\
\text { min-max }\end{array}$ \\
\hline T651 & $460-505$ & $530-570$ & 10 & $140-160$ \\
\hline
\end{tabular}

Kesici takım olarak demir dışı metaller için kullanılan ISO K10 standardında Tagutech marka sinterlenmiş karbür takımlar kullanılmıştır. Çalışmada kullanılan takımlar sırasıyla şöyledir;

T1: TCMT 16T308 MT K10 (Kaplamasız karbür) UC

T2: TCGT 16T308 FL K10 (Alüminyum için ticari kaplamalı) CC

T3: TCMT 16T308 MT K10 + DLC (DLC Kaplanmış karbür) DLC 
Görüldüğü gibi çalışmada sırasıyla kaplamasız (T1), ticari kaplamalı (T2) ve Atatürk Üniversitesi laboratuvarlarında özel DLC kaplama yapılmış takım (T3) kullanılmıştır. Kıyaslama yapılabilmesi için, ana takım malzemesi aynı tutulmuş, yalnızca kaplama şartları değiştirilmiştir. Takımın geometrisi ve boyutları Şekil 1'de verilmiştir.

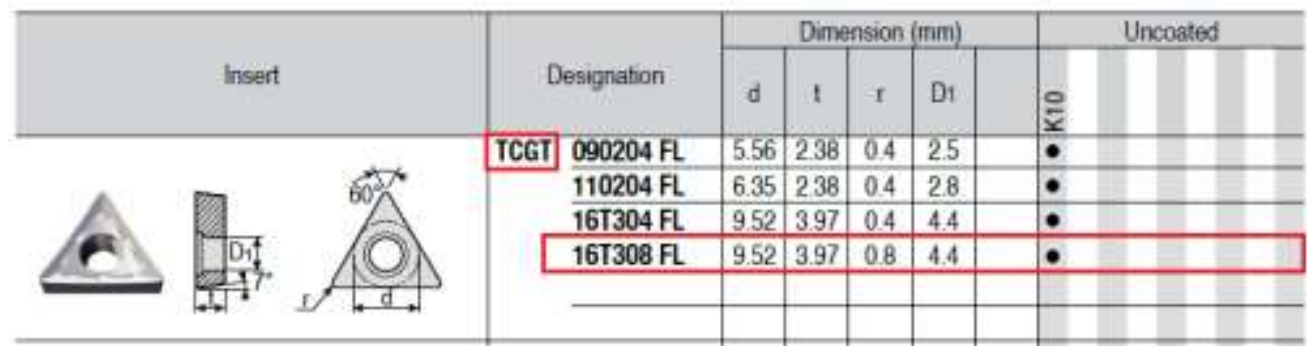

Şekil 1. Kesici takım bilgileri (Firma Kataloğu)

T3 takım üzerine özel DLC kaplama yapılmadan önce ISO K10 standardındaki kaplamasız karbür kesici takımlar, kobalt içeriğini azaltmak ve takım yüzeyini pürüzlendirmek için literatür ışığında [23] belirlenen murakami çözeltisi (10g Ferrosiyanid $\left(\mathrm{K}_{3}[\mathrm{Fe}(\mathrm{CN})]_{6}\right)+10 \mathrm{~g}$ potasyum hidroksid $(\mathrm{KOH})$ $\left.+100 \mathrm{ml} \mathrm{su}\left(\mathrm{H}_{2} \mathrm{O}\right)\right)$ içerisinde ultrasonik olarak 30 dakika bekletilmiş ve daha sonra alkolle yıkanıp kurutulmuştur. K10 karbür takım üzerine DLC kaplama işlemi; PVD (CFUBMS-Kapalı alan dengelenmemiş manyetik alanda sıçratma) yöntemi kullanılarak Ti esaslı hidrojen dope edilmiş olarak gerçekleştirilmiştir. Kaplama 0,3 Pa vakum basıncında, 20 dakika iyon temizleme işleminden sonra sırasıyla 5 dakika Ti kaplama, 10'ar dakika \%55 azot akışı altında TiN ve TiCN kaplama şeklinde çok katmanlı uygulanmıştır. Son aşamada $15^{\prime}$ er dakikalık iki dilim halinde \%55-\%25 aralığında azaltılmış $\mathrm{C}_{2} \mathrm{H}_{2}$ (Etin) ve \%7 azot akışı altında DLC kaplama şeklinde uygulanmıştır. DLC kaplama işlemi toplam 55 dakika sürmüştür.

Kesici takımı tezgâha bağlamak için, Takımsaş marka STGCL 2525 M16 modeli takım tutucu kater kullanılmıştır (Şekil 2). Talaşlı imalat işlemi dik (orthogonal) kesme olarak gerçekleştirilmiştir.
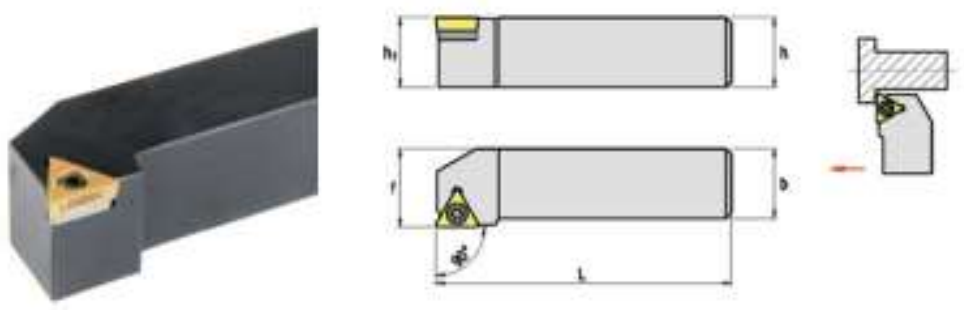

Şekil 2. Çalışmada kullanılan takım tutucu ve takımın geometrik özellikleri

Çalışmada bağımsız değişken olarak, kesme hızı, ilerleme hızı ve kesici takım belirlenmiş ve bunların seviyeleri Tablo 3' de verilmiştir. Talaş derinliği ise 1,5 mm olarak sabit alınmıştır. İş parçası ayna-punta arasına alınarak $230 \mathrm{~mm}$ 'lik kısmı orthogonal tornalama yapılmıştır. Kesme sırasında Kistler marka 9257-B modeli dinamometre ve 5070-A 11100 tipi amplifikatör kullanılarak kesme kuvvetleri ölçülmüş, takım temas yüzeylerinin sem analizi yapılmış ve her bir kesme işlemi için talaş geometrileri görüntülenmiştir. Ayrıca parçaların yüzey pürüzlülüğü de Hommel Werke marka T 500 modeli yüzey pürüzlülük ölçüm cihazı ile ölçülmüştür.

Tablo 3. Kesme parametreleri ve değerleri

\begin{tabular}{|c|c|c|c|}
\hline Parametreler & $\begin{array}{c}(\mathrm{A}) \\
\mathrm{V}(\text { Kesme hız1) }[\mathrm{m} / \mathrm{dk}]\end{array}$ & $\begin{array}{c}\text { (B) } \\
\mathrm{F} \text { (İlerleme) }[\mathrm{mm} / \mathrm{dev}]\end{array}$ & $\begin{array}{c}\text { (C) } \\
\text { Kesici Takım }\end{array}$ \\
\hline Seviye 1 & 300 & 0,2 & T1 UC (Kaplamasız karbür) \\
\hline Seviye 2 & 400 & 0,3 & T2 CC (Kaplamalı karbür) \\
\hline Seviye 3 & 500 & 0,4 & T3 DLC (Elmas kaplamalı) \\
\hline
\end{tabular}


Taguchi L9 deney tasarımına göre belirlenen kesme parametreleri ise Tablo 4'de verilmiştir. Bu deney tasarımı tam faktöriyel 27 deney içerisinden belirlenmiştir. Bu çalışmada gerçekleştirilen deneysel çalışmalarda Tablo 4'deki parametreler kullanılmıştır.

Tablo 4. Deney parametreleri ve seviyeleri

\begin{tabular}{|c|c|c|c|l|}
\hline $\begin{array}{c}\text { Deney } \\
\text { No }\end{array}$ & Değişkenler & $\begin{array}{c}\text { (A) } \\
\text { V (Kesme hız1) }[\mathrm{m} / \mathrm{dk}]\end{array}$ & $\begin{array}{c}\text { (B) } \\
\text { F (Illerleme) }[\mathrm{mm} / \mathrm{dev}]\end{array}$ & \multicolumn{1}{|c|}{ Kesici Takım } \\
\hline 1 & A1B1C1 & 300 & 0,2 & T1 UC \\
\hline 2 & A1B2C2 & 300 & 0,3 & T2 CC \\
\hline 3 & A1B3C3 & 300 & 0,4 & T3 DLC \\
\hline 4 & A2B3C1 & 400 & 0,4 & T1 UC \\
\hline 5 & A2B1C2 & 400 & 0,2 & T2 CC \\
\hline 6 & A2B2C3 & 400 & 0,3 & T3 DLC \\
\hline 7 & A3B2C1 & 500 & 0,3 & T1 UC \\
\hline 8 & A3B3C2 & 500 & 0,4 & T2 CC \\
\hline 9 & A3B1C3 & 500 & 0,2 & T3 DLC \\
\hline
\end{tabular}

\section{Bulgular ve Tartışma}

Dövme alüminyum alaşımlarından, 7075-T651 (yaşlandırılmış ve temperlenmiş) malzemenin dik tornalanması sırasında karbür kesici takımın performansı ve yaygın sorunlarına bir çözüm arama amacıyla DLC kaplamanın performansının incelendiği bu çalışmada farklı kesme şartları altında talaş formları ve yüzey pürüzlülüğü değerleri elde edilmiş ve değerlendirilmiş̧tir. Talaş derinliğinin $1,5 \mathrm{~mm}$ olarak sabit alındığı çalışmada, ilk olarak literatür ışığında belirlenen 300,400 ve $500 \mathrm{~m} / \mathrm{dk}$ olmak üzere 3 farklı kesme hızı, 0,2-0,3 ve 0,4 mm/dev olmak üzere 3 farklı ilerleme değeri kesme parametreleriyle, 3 farklı kaplama şartlarındaki kesici takım için talaş form kartı elde edilmiş ve Şekil 3'de verilmiştir.

Farklı kesme parametrelerinde oluşan talaş formları incelendiğinde (Şekil 3), tüm kesici takımlar için genel değerlendirmede, düşük kesme hızı ve ilerleme değerlerinde daha uzun talaş formlarının görüldüğg̈ söylenebilir. Bu durum düşük kesme parametrelerinde talaş-temas uzunluğunun büyük olduğu, kesme parametrelerinin artmasıyla talaş uzunluğunun ve dolayısıyla takım-talaş temas uzunluğunun azaldı̆̆ 1 şeklinde yorumlanabilir.

Talaşların mikroskop altında daha detaylı morfolojik incelemeleri Şekil 4'de verilmiştir. Burada talaş segmentasyonları net olarak görülebilmektedir. Talaş segmentasyon fenomeni, talaş parçalanmasını teşvik ettiği için işleme sırasında istenen bir talaş oluşturma mekanizmasıdır. Talaş segmentasyonunun frekans1, deformasyonun derecesiyle ilgilidir. 


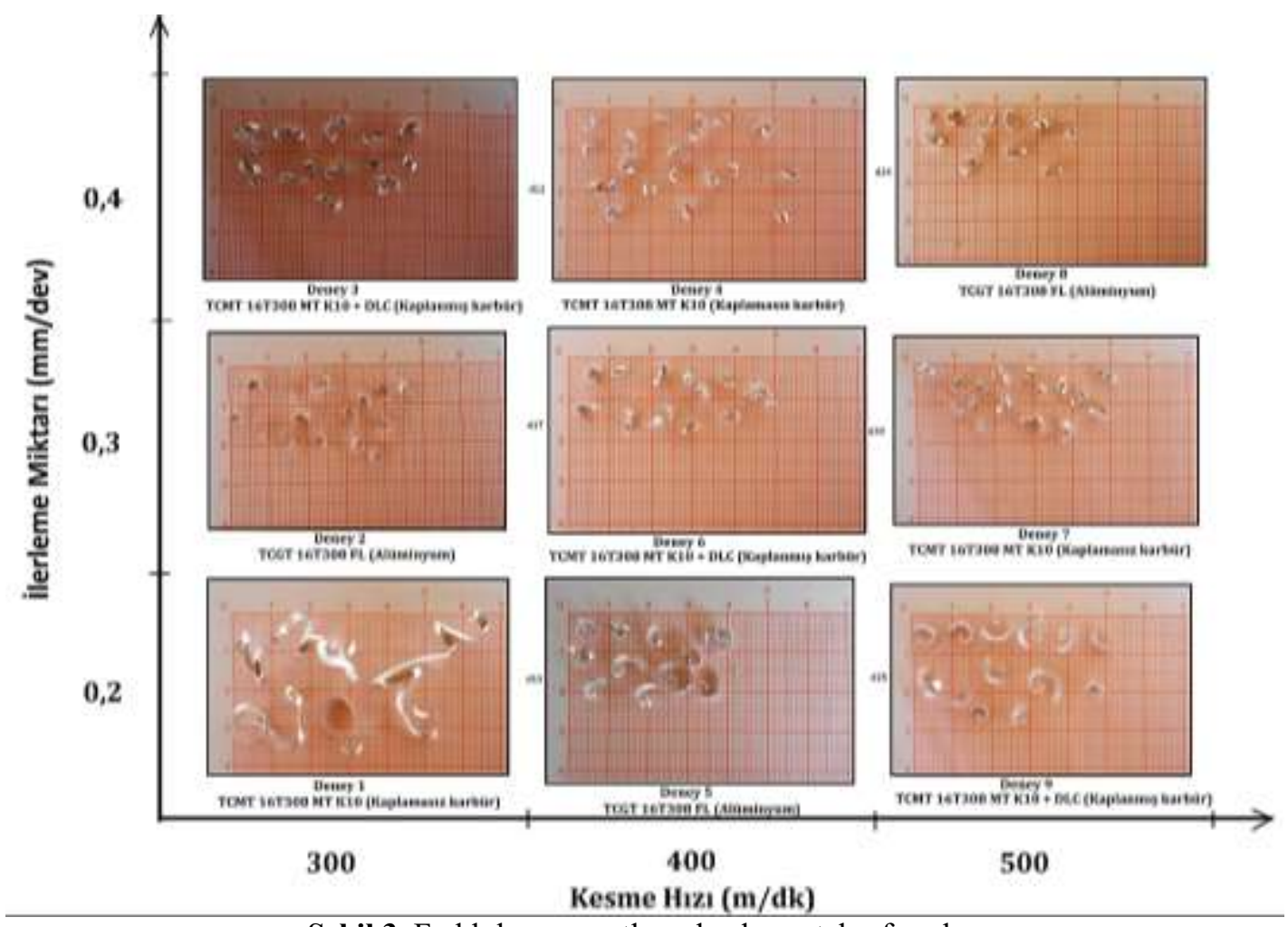

Şekil 3. Farklı kesme şartlarında oluşan talaş formları

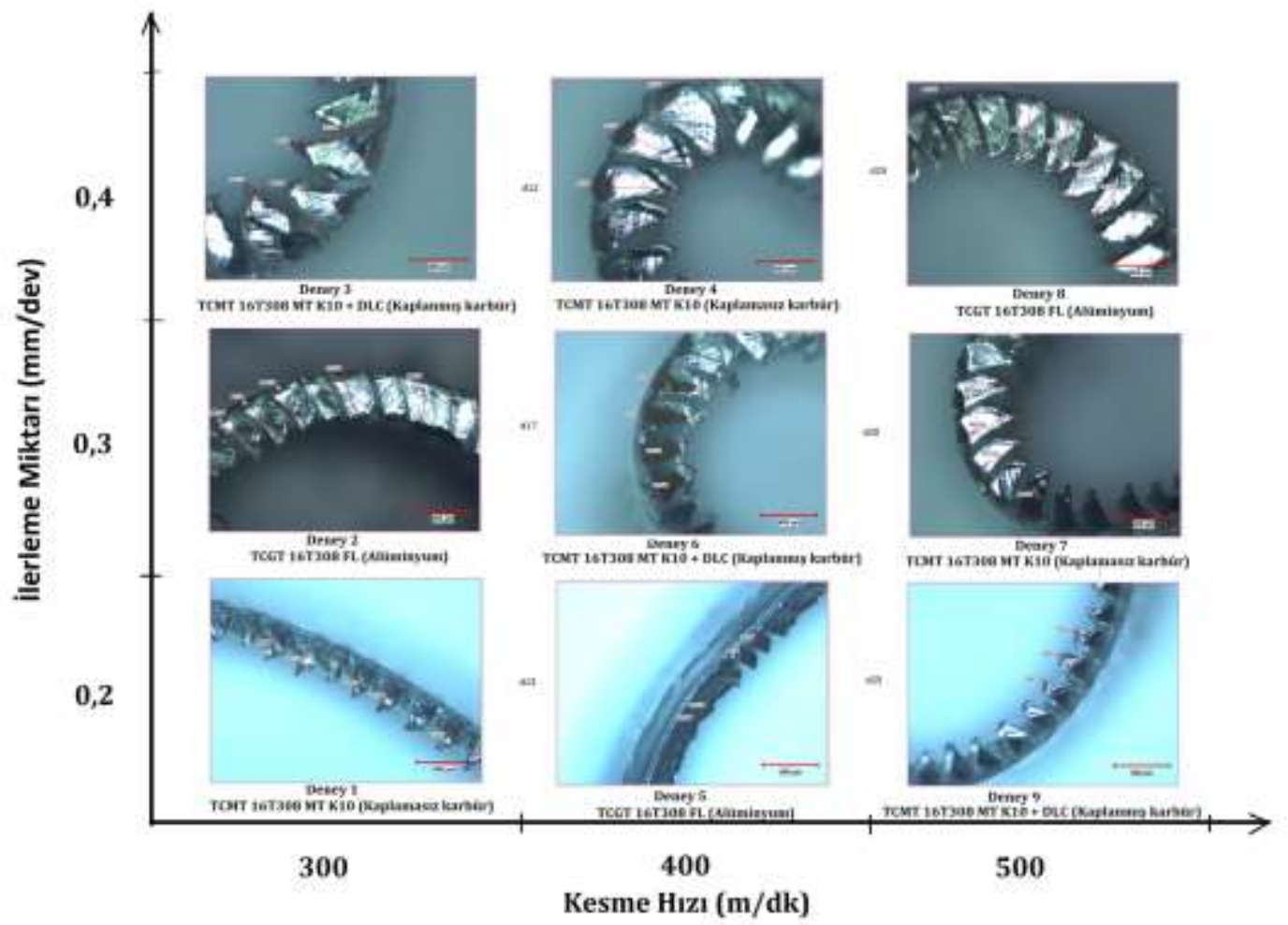

Şekil 4. Farklı kesme şartlarında oluşan talaş formlarının morfolojisi

Kaplamasız takımda hatve daha fazla olduğundan, kaplanmış kesici takımın kaplanmamış olandan daha fazla Fz'ye (ilerleme kuvveti) karşılık geldiği açıktır. Kaplamasız takımda azalmış segmentasyon frekansı, daha yüksek miktarda yan yüzey aşınmasına bağlı olabilir. Bu nedenle, daha düşük takım aşınması nedeniyle kaplanmış karbür takımda daha düşük bir segmentasyon frekansı gözlemlenmiştir [1] 
DLC kaplamalı karbür takım ile en düşük ilerleme, en yüksek kesme hızında talaş segmentasyon yüksekliği $225 \mu \mathrm{m}$ mertebesinde iken, ilerlemenin en yüksek kesme hızının ise en düşük olduğu durumda $620 \mu \mathrm{m}$ olarak ölçülmüştür. Yüksek ilerleme, düşük kesme hızında talaş segmentasyon yüksekliğinin artması eğilimi kaplamasız ve ticari kaplamalı takımda da görülmüştür.

En düşük ilerleme (f:0,2 mm/dev) ve kesme hızında (Vc:300 m/dk) kaplamasız karbür takımtalaş temas alanı daha büyük ve talaş yığılması (BUE) bariz bir şekilde görülmektedir (Şekil 5.a). Aynı takım için ilerlemenin en yüksek kesme hızının ise en düşük olduğu durumda kesme hızının artması nedeniyle talaş yığılması görülmemiştir (Şekil 5.b). Düşük kesme hızlarında takım-talaş temas bölgesinin tamamında, talaşın takım yüzeyine sıvanması beklenen bir durumdur [24]. Özellikle sünek malzemelerde düşük kesme hızlarında, temas yüzeyinde talaş yığıllması ve sıvanma yoğun olarak görülecektir. Kesme hızının artmasıyla yığıntı talaş eğiliminin azaldığı görülmektedir. Diğer taraftan kesme hızının artmasıyla, takım-talaş temas bölgesinde, yüksek sıcaklık, yüksek gerilim ve gerinim (deformasyon) şartlarının oluşacağı ve bu durumun malzemenin sünekliğini ve takım yüzeyine sıvanma eğilimini artıracağını ifade eden çalışmalarda bulunmaktadır [25]. Burada kesme şartları ve kesici takım malzemesi ve yüzey durumuna bağlı olarak değişen ve baskın olan işleme mekanizmasının tespiti için daha detaylı analizlerin yapılması gerekmektedir.

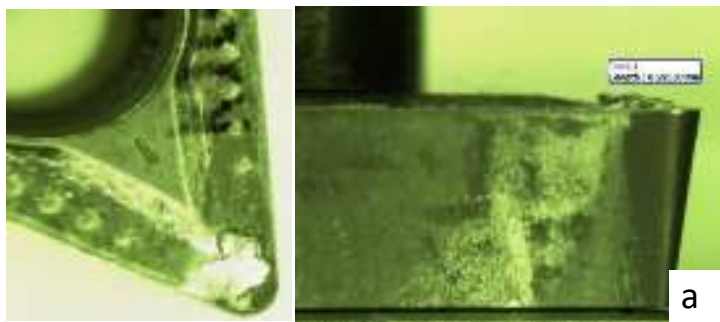

T1 takım, f:0,2 mm/dev, $V_{c}: 300 \mathrm{~m} / \mathrm{dk}$

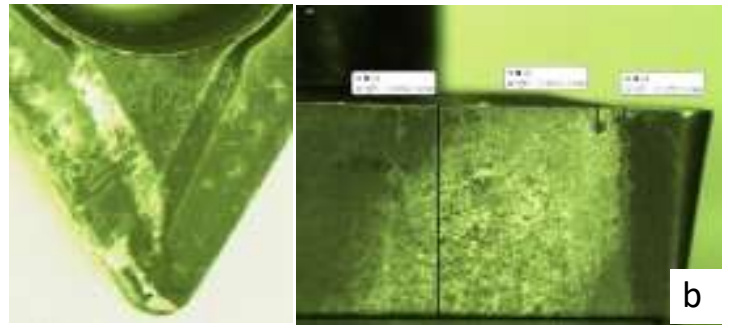

T1 takım, f:0,2 mm/dev, Vc:500 m/dk

Şekil 5. Kaplamasız karbür takımın aynı ilerleme değeri için a)düşük kesme hızında b)yüksek kesme hızında talaş yüzeyi ve yan yüzey optik mikroskop görüntüleri

$\mathrm{Bu}$ çalışmanın kapsamı içerisinde yapılan, kaplamasız karbür takımın f: 0,2 mm/dev Vc: 300 $\mathrm{m} / \mathrm{dk}$ şartlarında aşınma bölgelerindeki EDS elementel analiz sonuçlarına göre, takım yüzeyinde alüminyum malzemenin sıvandığı bariz bir şekilde görülmektedir (Şekil 6).

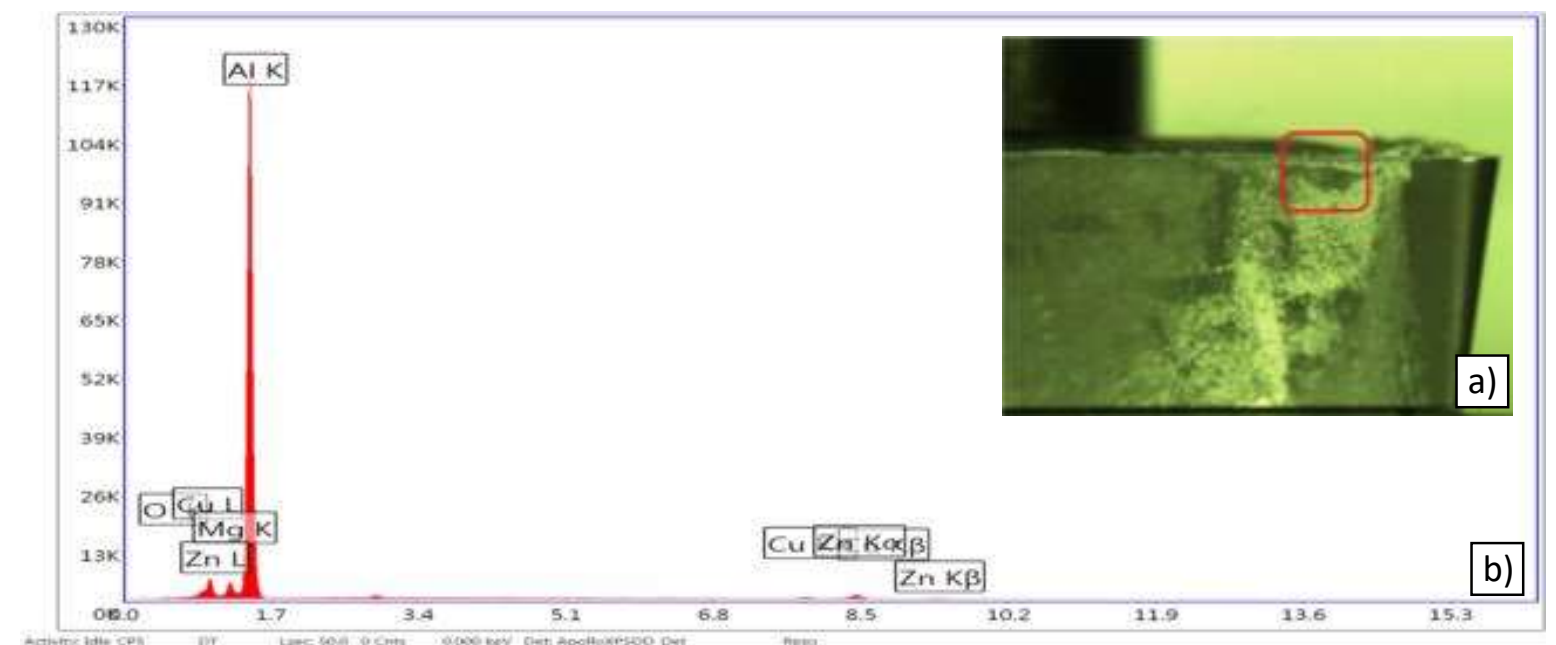

Şekil 6. Kaplamasız karbür takımın f: 0,2 mm/dev, Vc: $300 \mathrm{~m} / \mathrm{dk}$ şartlarında işleme sonrası aşınma için a) Takımda incelenen bölge, b) EDAX EDS Elementel analiz sonuçları

b)

Karşılaştırma için DLC kaplamalı takım için de en düşük ilerleme ve kesme hızı ile ilerleme değeri aynı kalmak şartıyla kesme hızının arttırıldığı durum için takım yüzey optik görüntüleri Şekil 7'de verilmiştir. DLC kaplamayla takım üzerinde yığıntı talaş görülmemekle birlikte, takım talaş 
yüzeyinde yapılan EDS elementel analiz sonuçlarında takım yüzeyinde yer yer düşükte olsa alüminyum kalıntılarına rastlanmıştır.
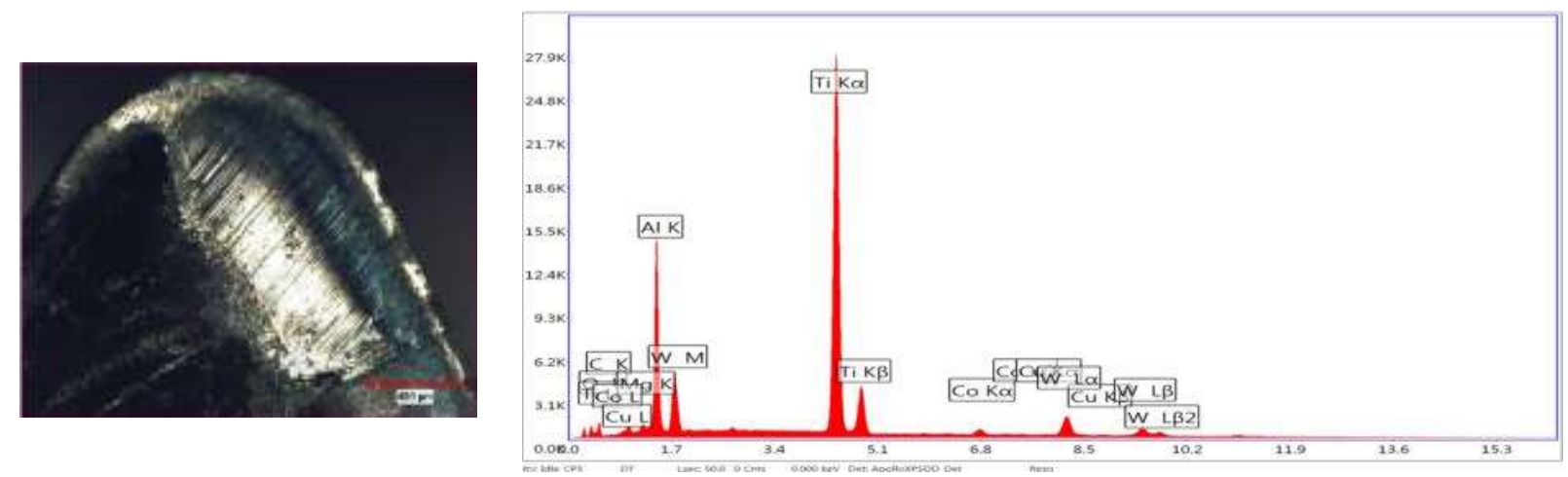

Şekil 7. DLC kaplamalı takımla f: $0,2 \mathrm{~mm} / \mathrm{dev} \mathrm{Vc}: 300 \mathrm{~m} / \mathrm{dk}$ şartlarında işleme sonrası talaş yüzeyindeki aşınma bölgelerinde yapılan EDAX EDS elementel analiz sonuçları

DLC kaplamalı takımla ilerleme değeri en düşük değerinde kalırken, kesme hızı en yüksek değerine ulaştığında yine takım talaş yüzeyinde yapılan EDS elementel analiz sonuçları ise Şekil 8'de verilmiştir. Yüksek kesme hızında DLC kaplamanın talaş sıvanma eğilimini büyük oranda azalttığı görülmektedir (Şekil 8.).
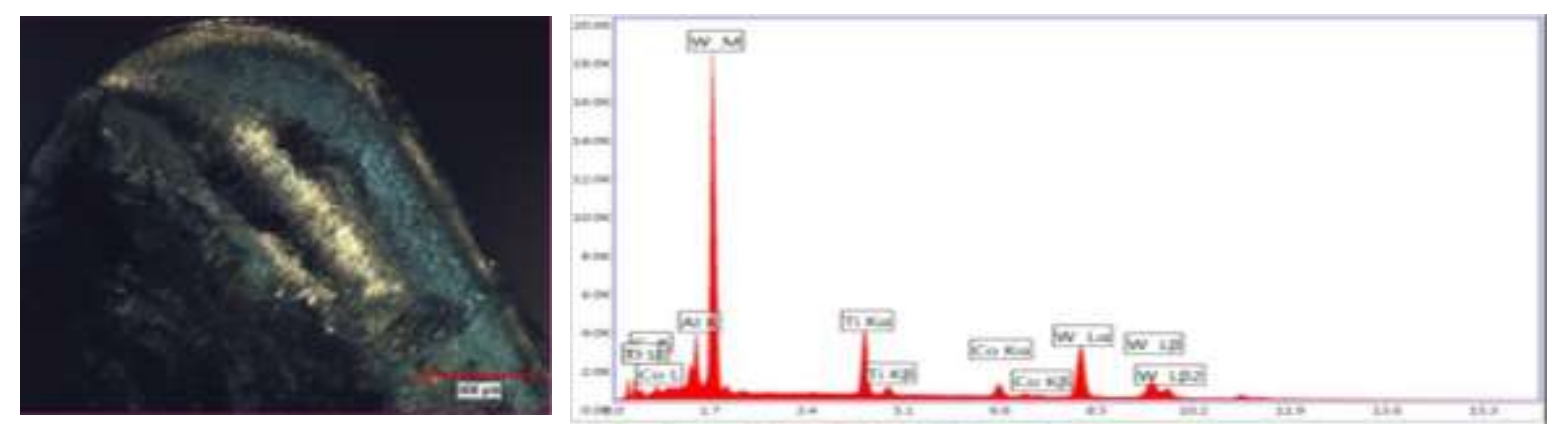

Şekil 8. DLC kaplamalı takımla f: $0,2 \mathrm{~mm} / \mathrm{dev} V \mathrm{~V}: 500 \mathrm{~m} / \mathrm{dk}$ ) şartlarında işleme sonrası talaş yüzeyindeki aşınma bölgelerinde yapılan EDAX EDS elementel analiz sonuçları

Bu çalışmada DLC kaplamanın Al 7075-T651 a dövme alüminyum alaşımı özelinde talaş yığılması ve sıvanma sorununa bir çözüm olabilmesini sorgulamaya yönelik yapılan ön deneysel çalışmaları kapsamaktadır. Tornalama işlemi sırasında elde edilen talaş formlarının SEM analizleri ile kesici takım aşınma yüzeylerinin mikroskop görüntüleri ve EDS elementel analizi sonuçlarına dayanarak DLC kaplamanın sıvanma sorununa çözüm olabileceği sonucuna varılmıştır. Yapılan yüzey pürüzlülük ölçümlerinde tüm deneyler sonuçları için en düşük Ra değeri DLC kaplamalı takımla en düşük ilerleme ( $\mathrm{f}=0,2 \mathrm{~mm} / \mathrm{dev})$ ve en yüksek kesme hızı $(\mathrm{Vc}=500 \mathrm{~m} / \mathrm{dk})$ kesme şartlarında $\mathrm{Ra}=1,57$ $\mu \mathrm{m}$ olarak elde edilmiştir. Aynı kesme parametrelerinde esas kesme kuvveti de en düşük değerde $(\mathrm{Fc}=$ 293,88 N) ölçülmüştür. Ancak aynı takım için, ilerlemenin yüksek ( $\mathrm{f}=0,4 \mathrm{~mm} / \mathrm{dev})$ kesme hızının ise en düşük $(\mathrm{Vc}=300 \mathrm{~m} / \mathrm{dk})$ olduğu kesme şartlarında ise yüzey pürüzlülüğü $\mathrm{Ra}=6,47 \mu \mathrm{m}$, kesme kuvveti $\mathrm{Fc}=$ 509,79 $\mathrm{N}$ mertebesine ulaşmaktadır. Bu ise ilerleme ve kesme hızı parametrelerinin Al 7075-T651 alaşımının kesme şartlarını önemli oranda etkilediğini göstermiştir.

\section{Sonuç ve Öneriler}

Ergime sıcaklığ düşük ve sünek bir malzeme olan alüminyum alaşımlarının bilinen işleme problemlerinden yığıntı talaş ve takım-talaş ara yüzeyinde sıvanma için özgün bir DLC kaplama yönteminin performansı hakkında deneysel olarak bir ön çalışma niteliğinde yapılan çalışmada aşağıdaki sonuçlar elde edilmiştir. 
I. Kesme parametreleri (kesme hızı, ilerleme) kesici takımın ve iş parçası malzemesinin kesme esnasındaki malzeme özelliklerini önemli ölçüde etkilemekte ve takım performansının belirlemektedir. Bu çalışmada en iyi kesme performansı en düşük ilerleme değeri $\mathrm{f}=0,2 \mathrm{~mm} / \mathrm{dev}$ ve en yüksek kesme hızı $\mathrm{Vc}=500 \mathrm{~m} / \mathrm{dk}$ için elde edilmiştir.

II. Kesme parametreleri aynı zamanda oluşacak kesme sıcaklığını ve buna bağlı olarak ta iş parçası malzemesinin özelliklerini, kesici takımın ve varsa kaplamanın performansını etkilemekte ve kesme mekanizmasını belirlemektedir. İşlenen alaşımın ve kesici takımın yüzey, ısıl ve mekanik özellikleri dikkate alınarak kesme parametrelerinin optimize edilmesi önemlidir. Genelde alüminyum alaşımlarının talaşlı imalatında kesici takımlarda en yaygın görülen temel aşınma mekanizması adezyon olurken, temel aşınma tipinin yığıntı talaş (BUE) olduğu literatür 1şı̧ı̆ında değerlendirilmiştir [1]. Bu çalışmada da özellikle kaplamasız karbür takımda adezyon aşınma mekanizmasıyla oluşan kenar yığılması görülmüştür.

III. Genel olarak, yüzey merkezli kübik yapıya sahip alüminyum alaşımlarının sünek yapısı nedeniyle işleme sırasında kesme kuvvetleri artmakta, buna bağlı olarak zayıf yüzey kalitesi ve talaş kontrolü söz konusudur. Al 7075-T651 alaşımları ise diğer 1sıl işlem görebilir (2xxx ve 6xxx serisi) alaşımlarla birlikte, gördüğü 1sıl işlemden dolayı nispeten sünekliği azalmış, mukavemeti artmış bir alaşım olarak malzeme yapısında sünek/gevrek geçiş formları da içerdiğinden [26] ayrı değerlendirilmelidir.

IV. DLC kaplama 7075-T651 alüminyum alaşımlarında takım-talaş ara yüzeyinde yapışmayı önleyici şartları sağlamaktadır. Daha iyi sonuçların alınabilmesi için DLC kaplama proses parametrelerinin (hidrojen oran1, sp3 bağ yapıs1, iyon enerjisi, vakum basınc1, biriktirme süresi ve sıcaklığı vb.) optimize yönündeki çalışmalar önerilebilir.

\section{Yazarların Katkısı}

Yazarlar makaleye eşit oranda katkı sağlamış olduklarını beyan eder.

\section{Çıkar Çatışması Beyanı}

Yazarlar arasında herhangi bir potansiyel çıkar çatışması bulunmamaktadır.

\section{Araştırma ve Yayın Etiği Beyanı}

Yapılan çalışmada araştırma ve yayın etiğine uyulmuştur.

\section{Kaynaklar}

[1] Sahoo A.P., Datta S. 2020. Dry Machining Performance of AA7075-T6 Alloy Using Uncoated Carbide and MT-CVD TiCN-Al2O3-Coated Carbide Inserts. Arabian Journal for Science and Engineering, 45:9777-9791.

[2] Mandal K.K., Mitra S. 2018. Experimental investigation on laser micro-machining of Al 7075 Alloy. Optics and Laser Technology, 107: 260-267.

[3] Editors; Carou D., Davim J.P. 2019. Machining of Light Alloys: Aluminum, Titanium and Magnesium. CRC Press Taylor Francis Group, Broken Sound Parkway NW.

[4] Hovsepian P.E., Luo Q., Robinson G., Pittman M., Howarth M., Doerwalt D., Tietema R., Sim W.M., Deeming A., Zeus T. 2006. TiAlN/VN superlattice structured PVD coatings: A new alternative in machining of aluminum alloys for aerospace and automotive components. Surface Coating Technology, 201: 265-272.

[5] Campell C.E., Bendersky L.A., Boettinger W.J., Ivester R. 2006. Microstructural characterization of Al-7075-T651 chips and work pieces produced by high-speed machining. Materials Science and Engineering A, 430: 15-26.

[6] Santos G.R., da Costa D.D., Amorim F.L., Torres R.D. 2007. Characterization of DLC thin film and evaluation of machining forces using coated inserts in turning of Al-Si alloys. Surface and Coating Technology, 202 (4-7): 1029-1033. 
[7] Brzezinka T.L., Rao J., Paiva J.M., Kohlscheen Fox-Rabinovich G.S., Veldhuis S.C., Endrino J.L. 2019. DLC and DLC-WS2 Coatings for Machining of Aluminum Alloys, Coating. 9 (192): $1-15$.

[8] Altunpak Y., Akbulut H. 2009. Effects of aging heat treatment on machinability of alümina short fiber reinforced LM 13 aluminum alloy. Int. J. Advanced Manufacturing Technology, 43:449454.

[9] Wieronski P., Pezda J., Ponikwia L. 2016. Effect of Heat Treatment on Machining Properties of the AlSi9Cu3(Fe) Alloy. Archives of Foundry Engineering, 16 (3): 137-140

[10] Jarco A., Pezda J. 2016. Effect of Different Variants of Heat Treatment on Mechanical Properties of the AlSi17CuNiMg Alloy. Archives of Foundry Engineering, 16 (2): 41-44

[11] List G., Nouari M., Gehin D., Gomez S., Manaud J.P., Le Petitcorps Y., Girot F. 2005. Wear behaviour of cemented carbide tools in dry machining of aluminum alloy. Wear, 259: 1177-1189.

[12] Kouadri S., Necib K., Atlati S., Haddag B., Nouari M. 2013. Quantification of the chip segmentation in metal machining: Application to machining the aeronautical aluminum alloy AA2024-T351 with cemented carbide tools WC-Co. Int. J. Machine Tool \& Manufacture, 64: 102-113.

[13] Salguero J., Batista M., Calamaz M., Girot F., Marcos M, 2013. Cutting Forces Parametric Model for the Dry High-Speed Contour Milling of Aerospace Aluminum Alloys. Procedia Engineering, 63: 735-742.

[14] Rao K.S.S., Allamraju K.V. 2017. Effect on Micro-Hardness and Residual Stress in CNC Turning of Aluminum 7075 Alloy. (ICMPC 2016) Materials Today:Proceedings, 4: 975-981.

[15] Wakabayashi T., ve Suda S. 2008. Environmentally friendly machining of aluminum using minimal quantity lubrication system. Proceedings of 41st CIRP Conference on Manufacturing Systems, Tokyo, Japan, 377-380.

[16] Sreejith P.S. 2008. Machining of 6061 aluminum alloy with MQL, dry and flooded lubricant conditions. Materials Letters, 62: 276-278.

[17] Çakır A., Yağmur S., Kavak N., Küçüktürk G., Şeker U. 2016. The effect of minimum quantity lubrication under different parameters in the turning of AA7075 and AA2024 aluminum alloys. Int. J. Manufacturing Technology, 84: 2515-2521.

[18] Singh T., Singh J., Singh M. 2016. Drilling of 6061 Aluminum Alloy with MQL, Dry and Flooded Cooling-Lubricant Conditions. IJRMET, 6 (2): 58-60.

[19] Roy P., Sarangi S.K., Ghosh A., Chattopadhyay A.K. 2009. Machinability study of pure aluminum and $\mathrm{Al}-12 \% \mathrm{Si}$ alloys against uncoated and coated carbide inserts. Int. J. Refractory Metals \& Hard Materials, 27: 535-544.

[20] Gangopadhyay S., Acharya R., Chattopadhyay A.K., Sargade V.G. 2010. Effect of cutting speed and surface chemistry of cutting tools on the formation of BUL or BUE and surface quality of the generated surface in dry turning of AA6005 aluminum alloy. Machining Science and Technology, 14: 208-223.

[21] Lei X., Shen B., Sun F. 2015. Optimization of diamond coated microdrills in aluminum alloy 7075 machining: A case study. Diamond \& Related Materials, 54: 79-90.

[22] Patnaik S.K., Bhoi N.K., Padhi S., Sarangi S.K. 2018. Dry machining of aluminum for proper selection of cutting tool: tool performance and tool wear, Int. J. Advanced Manufacturing Technology, 98: 55-65.

[23] Miao J., Song J., Xue Y., Tong Y., Tang W., Lu F. 2004. Effect of a two-step pretreatment method on adhesion of CVD diamond coatings on cemented carbide substrates. Surface Coating \& Technology, 187: 33-36.

[24] Kılıç D.S., Raman S. 2007. Observations of the tool-chip boundary conditions in turning of aluminum alloys. Wear 262: 889-904.

[25] Santos M.C., Machado A.R., Sales W.F., Barrozo M.A.S., Ezugvu E.O. 2016. Machining of aluminum alloys: a review. Int. J. Advanced Manufacturing Technology, 86: 3067-3080.

[26] Imbrogno S., Rinaldi S., Suarez A.G., Arrazola J., Umbrello D. 2018. High speed machinability of the aerospace alloy AA7075 T6 under different cooling condition. Proceedings of the 21st International ESAFORM Conference on Material Forming, AIP Conf. Proc. 1960, 070013; doi: $10.1063 / 1.5034909$ 